\title{
Emotional Intelligence as a Mediator between Teachers' Emotional Mistreatment and Long-Term Emotional Impact on Students
}

\author{
Bat Katzman1, Niva Dolev1, Meni Koslowsky ${ }^{2 *}$ \\ ${ }^{1}$ Kinneret College on the Sea of Galilee, Zemac, Israel \\ ${ }^{2}$ Ariel University, Ariel, Israel \\ Email: ^Koslowsme8@gmail.com
}

How to cite this paper: Katzman, B., Dolev, N., \& Koslowsky, M. (2021). Emotional Intelligence as a Mediator between Teachers' Emotional Mistreatment and LongTerm Emotional Impact on Students. Psychology, 12, 304-319.

https://doi.org/10.4236/psych.2021.122020

Received: January 21, 2021

Accepted: February 23, 2021

Published: February 26, 2021

Copyright $\odot 2021$ by author(s) and Scientific Research Publishing Inc. This work is licensed under the Creative Commons Attribution International License (CC BY 4.0).

http://creativecommons.org/licenses/by/4.0/

\begin{abstract}
Teacher emotional mistreatment, which includes both verbal and nonverbal abusive behaviors, is a widespread and harmful experience for school students. However, its long-term emotional impacts remain relatively unexplored. This study explored the mediating role of emotional intelligence (EI) on the association between teacher's emotional mistreatment towards school children and the long-term emotional impact on the students. A total of 377 Israeli Arab students in different stages of their university training completed the Psychological Maltreatment Subscale Questionnaire on teacher's mistreatment while they were in school, and the Wong and Law EI Scale. The longterm emotional impact was measured using a tool developed especially for the study. Results revealed that $31 \%$ of the participants reported being mistreated by teachers at least once. The most reported long-term emotional impacts were feeling defensive, feeling a constant need to prove their worth, and fearing not to be perceived as lazy. Teacher mistreatment had significant long-term emotional impacts and was negatively correlated with EI. EI further acted as a significant mediator in the links between teacher mistreatment and its long-term emotional impact, with an indirect effect of .03. Raising awareness among teachers as to possible long-term emotional effects of abusive behaviors may help decrease mistreatment in the future. Determining the long-term impact of emotional mistreatment on social-emotional skills can help explain and prevent various types of negative outcomes in those students at a later stage in life.
\end{abstract}

\section{Keywords}

Emotional Intelligence (EI), Emotional Mistreatment, Long-Term Emotional Impact, Teacher Behavior 


\section{Introduction}

Outside of the immediate family, teachers constitute the group that has the most frequent and continuous contact with children until they finish high school (Goldman, 2010). These interactions with teachers are central to a students' school experience (Roorda et al., 2011) and have the potential to significantly affect cognitive and emotional development, as well as behaviors (Dahal et al., 2019; Gehlbach et al., 2012).

Indeed, while in the past attention has been given mainly to academic-related aspects of the school experience (Aroas, 2018), the emotional and social dimensions of teaching and learning are becoming increasingly recognized (Dewaele et al., 2018; Gasser et al., 2018; Kelchtermans, 2016). Emotions manifest themselves more frequently and at higher intensity among teachers than in many other professions (Nias, 1996). Emotional intra-personal, inter-personal and inter-group aspects of school life interact in complex ways and underpin every facet of the teachers' work (MacFarlane, 2018). In particular, the intensive dynamic of interactions which take place between teachers and students (Aroas, 2018), evoke strong emotions in teachers, both positive and negative (Brackett and Katulak, 2006; Timostsuk and Ugaste, 2012). Teachers' emotions, in turn, impact on their social relationships with students (Palomera et al., 2008) and affect the feelings, thoughts and actions of students (Rodrigo-Ruiz, 2016) for better or for worse (Paul and Smith, 2000). More specifically, teacher-student relationships have been associated with students' academic achievements, work habits and school behaviors (Hamre and Pianta, 2001); school engagement (Roorda et al., 2011); well-being and sense of security and safely (Nearchou, 2018); self-esteem (Twemlow and Fonagy, 2005); openness to interactions, trust in others, and peer perception and acceptance (Hughes et al., 2001).

Until recently, researchers have focused mainly on effective teaching and the positive impact of teachers (Aroas, 2018). Such studies demonstrated that teachers can positively impact their students by creating safe and nurturing learning environments and establishing positive student-teacher relationships; by treating students as individuals with fairness, empathy and respect; by addressing diversity in students; and by setting goals and promoting enthusiasm and engagement in learning (Stronge, 2007; Twemlow et al., 2017; Wang et al., 2017).

Similarly, while mistreatment in organizations (Itzkovich, 2015), in the family (McEachern et al., 2008; Theoklitou et al., 2012; Zhao et al., 2020) and between students (Cowie and Mayers, 2017; Hicks et al., 2018) have become growing areas of study, teachers' mistreatment towards students has not been investigated adequately (Chen and Whi, 2011; Nearchou, 2018). This form of mistreatment is the most common type of teachers' harmful behaviors towards students (Aroas, 2018) and one which has particularly profound negative effects on them (Kizlltepe et al., 2020).

Several reasons can account for the paucity of research in this area. Firstly, emotional mistreatment is often subtle (Itzkovich, 2015), making the threshold 
for considering an act as abusive hard to determine, and its impact is often quite elusive (O'Dougherty-Wright, 2014). Thus, it is not easily detected by students (Aroas, 2018), and it is not uncommon to find students blaming themselves for being the cause of the teachers' behavior (Geiger, 2017). Teachers themselves are often unaware of their own inappropriate behaviors, and perceive them as harmless, or triggered as a response to students' misbehavior and aimed at re-directing them (Hogan et al., 2019; Longobardi et al., 2015). Lastly, this relatively limited scope of research can be also attributed to a more general existing erroneous assumption that since physical punishment is banned from Western schools, abusing disciplinary practices no longer exist (Geiger, 2017).

The small number of available studies indicates that there are wide ranging and severe negative consequences associated with teachers' mistreatment on the physical, emotional health, and well-being of students (Chen and Whi, 2011). These studies have generally focused on the prevalence of emotional teachers' mistreatment and its immediate impact on students and not on its long-term impact (Aroas, 2018; Nearchou, 2018). In addition, studies specifically addressing mediators explaining the long-term effects are lacking (O'Dougherty-Wright, 2014). Research in organizations (Bibi and Karim, 2013; Izkovich \& Dolev, 2017; Pearson and Porath, 2009) and families (Mattar, 2018; Zhao et al., 2020) have indicated that EI may very well play a role in how mistreatment eventually affects the individual. However, it was not yet tested in teachers' mistreatment context. As such, this measure will be included in the present research.

The current study's main goal is to narrow the existing gap in research on students' response to teachers' mistreatment and its possible long-term emotional impact by including EI in the relationship. Such an investigation is especially important as social-emotional skills have been noted as being critical for coping with life demands and challenges and for overall success and well-being (Bar-On, 2006), thus related to students present and future.

\subsection{Teacher Emotional Mistreatment towards Students}

Emotional mistreatment also appears in the professional literature under the term's psychological maltreatment, mental cruelty, mental injury, emotional neglect, and psychological battering (Whitted, 2005). As such, it can better be defined as patterns of verbal and nonverbal behaviors that do not include any physical contact between a teacher and a student. It has been described as "negative pedagogy" (Aluede et al., 2012) and has been found to lead to emotional, social, cognitive, and somatic consequences in students (Nearchou, 2018).

Teachers' mistreatment toward students appears to be a relatively widespread problem (Nearchou, 2018; Theoklitou et al., 2012; Whitted and Dupper, 2008), with students reporting such experiences at all grade levels (Ba-Saddik and Hattab, 2012; Chen and Whi, 2011). The abusive behavior can be targeted towards a specific student or many students at the same time and can be a one time or a recurring episode (Nesbit and Philpot, 2002; Paul and Smith, 2000), with some 
students even describing it as a daily occurrence (McEachern et al., 2008). For example, Theoklitou et al. (2012) noted that almost a third of the Cyprian students in their study reported experiencing emotional abuse, while Nearchou (2018) found that $64 \%$ of Greek students reported such abuse. In Israel, $29 \%$ of grade 4 - 6 students and almost a quarter of seven-to-eleven-year-old students surveyed (Benbenishty et al., 2002) reported experiencing at least one form of emotional mistreatment by their teacher.

Emotional mistreatment by teachers may include verbal behaviors, such as sarcasm, ridicule or denigrating statements. In addition, it may contain ignoring students, assigning homework to impose discipline and using punishment, which are considered non-verbal abusive behaviors (McEachern et al., 2008; Nesbit and Philpot, 2002). Among them, being ignored, picked up, yelled at, and denied help by teachers were found to be the most frequently reported abusive experiences in several studies (Nearchou, 2018; Theoklitou et al., 2012).

\subsection{Impacts of Teachers' Mistreatment}

Teacher mistreatment has been noted to have traumatic effects on children's development, (Nesbit and Philpott, 2002), and is reported by students as their worst school experiences, much more than peer abuse (Hyman and Snook, 1999).

Teachers' emotional mistreatment is especially harmful as it takes place within meaningful relationships in which students tend to put trust in their teachers and seek to establish meaningful affective relationship with them (Longobardi et al., 2015). When mistreatment takes place, trust in teachers is violated and students experience deep uncertainty (Nearchou, 2018), and a threat to their overall safety (Aroas, 2018). Furthermore, typical to other abusive behaviors (Pearson and Porath, 2009), such harmful interpersonal relations take place within a power hierarchy (Smith and Brain, 2000), from which students are unable to distance themselves (Longobardi et al., 2015).

Students' exposure to emotional mistreatment by teachers was found to be linked to a decrease in well-being, an increase in somatic stress (Brendgen et al., 2006), and various psychological traumas (Reza et al., 2020). In the academic sphere, it was linked to poor academic achievement (Kizlltepe et al., 2020), lack of school engagement (Roorda et al., 2011), decrease in cognitive resources and academic motivation (Aroas, 2018), and a loss of interest in teacher's opinions and the school (Geiger, 2017). Emotional mistreatment was further linked to emotional and behavioral problems (Kiziltepe et al., 2020; McEachern et al., 2008), reduced self-worth and confidence (Nearchou, 2018; Twemlow and Fonagy, 2005), low social-emotional adjustment (Hamre and Pianta, 2001; Skalická et al., 2015), disengagement from social activities and negative acceptance from peers (Hughes et al., 2001).

In contrast to studies within families (O’Dougherty-Wright, 2014), little attention has been paid to the long-term emotional impact of teachers' emotional mistreatment (Aroas, 2018). The few studies of the long-time impact of teacher 
mistreatment found behavior problems and academic difficulties among students in early adolescence (Brendgen et al., 2006) and in emerging adulthood (Brendgen et al., 2007). In a unique qualitative study, which dealt with older adults, participants, aged 50 - 60, reported feeling "frozen in time" and described emotional, psychological and identity effects that included enduring negative emotions, negative evaluations and difficulties in creating and maintaining meaningful relationships (Aroas, 2018).

\subsection{Emotional Intelligence and Teacher Mistreatment}

Experiences of mistreatment have been recognized to be emotional in nature and taking place in a social context (Itzkovich et al., 2020). It follows that social and emotional skills, such as these included in the concept of emotional intelligence (EI), may be related to mistreatment. Mistreatment elicits strong negative emotions from victims and comprises a major source of stress which has a potential negative impact on the individual (Zeidner et al., 2012). Mayer and Salovey (1997), pioneers of EI research, defined EI as involving the ability to identify and express emotions, to understand emotions and emotional knowledge in self and others, to assimilate emotions in thoughts, and to regulate both positive and negative emotions in self and others. Others have suggested wider definitions describing a set of emotional and social skills and competencies, which are manifested in behaviors and outcomes (Bar-On, 2006; Goleman, 2006).

A large number of studies have explored the links between EI and various life outcomes (Leberecht, 2018; Zeidner et al., 2012), including in the educational arena, for both students and teachers (Balluerka et al., 2016; Brackett and Katulak, 2006). Findings from studies conducted with adults included links between EI and psychological health (Brackett and Salovey, 2006), subjective well-being (Bar-On, 2006), both positive and negative attitudes (Miao et al., 2017), coping with stress (Zysberg et al., 2017), quality of social interactions (Fernandez-Berrocal and Ruiz, 2008), and success at work (Bar-On, 2006). In particular, EI was linked to effective teaching and student-teacher relationship (Haskett, 2003; Nathanson et al., 2016; Perry and Ball, 2007). EI skills in children and youth have also been linked to a variety of outcomes, among them: improved learning and academic achievements (MacCann et al., 2020); increase in quality social interactions (Brackett and Katulak, 2006) and pro-social behaviors (Rutledge et al., 2015).

More specifically, in the present study, it is suggested that the social and emotional foundation of EI provides a channel by which teacher mistreatment plays a role in many aspects of an individual's life (Itzkovich et al., 2020). Some previous studies have focused on EI as a moderator (Bibi and Karim, 2013) or as a precursor of mistreatment (Beltrán-Catalán et al., 2018; Kokkinos and Kipritsi, 2012). As concerns our study here, and consistent with several studies that have noted a direct impact of mistreatment on the ability to use EI skills in adults (Izkovich \& Dolev, 2017; Pearson and Porath, 2009; Thompson, 2010), we argue 
here that EI may explain certain outcomes related to mistreatment. Thus, childhood family emotional mistreatment has already been shown to predict to emotional impairment and dysfunction through its influence on children's EI (Mattar 2018; Zhao et al., 2020). Schwartz (2016), for example, found that higher frequency and severity of specific subtypes of childhood mistreatment predicted lower EI using both trait and ability models. It was further found that EI decreases when mistreatment increases and vice versa (Mattar, 2018).

In line with these findings and with the paucity of research regarding the impact of teacher mistreatment on students' EI, our research hypotheses are:

1) Teacher emotional mistreatment is positively correlated with long term negative emotional effects,

2) Teacher emotional mistreatment is negatively correlated with EI,

3a) EI is negatively correlated with long term negative emotional effects,

3b) EI mediates the relationship between teacher emotional mistreatment and long term negative emotional effects.

\section{Method}

\subsection{Participants}

The data in the present study were collected from 377 Arab speaking female students in Northern Israel, ranging in age from 18 to 52 years old $(\mathrm{M}=24.13$, $\mathrm{SD}=5.76, \mathrm{Mdn}=22.00)$. Almost half $(45.6 \%, \mathrm{~N}=172)$ were B.A students and most of the rest were M.A students $(49.9 \%, \mathrm{~N}=188)$. The sampling procedure is described below.

\subsection{Instruments}

Emotional mistreatment by teachers. The nature and extent of emotional mistreatment by teachers was measured using the Psychological Maltreatment Subscale (PMS; Whitted and Dupper, 2008). PMS is a 9-item self-report measure assessing the frequency of emotional experiences induced by a teacher within the school context. The instrument was a revised version of a scale developed by Hyman and Snook (2002). The nine items ask the student to indicate whether they experienced specific events in which the teacher was the offender. For example, two of the items were: "A teacher yelled at me", "A teacher would not help me when I asked for help". The measurement instrument was rated on a four-point scale (" 0 " = never to " 4 " $=4$ or more times). The Alpha Cronbach reliability coefficient for the original psychological scale was .86. (Whitted and Dupper, 2008) and .83 in the current study.

Emotional Intelligence. EI was measured with the 16-item Wong and Law Emotional Intelligence Scale (Wong and Law, 2002), one of the most used self-report EI measures, based on the Salovey-Mayer EI framework (Mayer and Salovey, 1997). It covers four EI dimensions: Self-Emotion Appraisal; Others' Emotion Appraisal; Use of Emotions; and Regulation of Emotions, each comprising four items. 
Participants were asked to indicate the extent to which they agreed with each statement on the associated EI questionnaires, using a 5-point Likert scale ranging from strongly disagree (1) to strongly agree (5). A sample statement was:

"I really understand what I feel". Alpha Cronbach reliability coefficients for the tool ranged from $.83-.90$ (Wong and Law, 2002), and in this study, for the all 16-items of the EI questionnaires was .88

Long Term Emotional Impact. The long-term emotional impact of teacher mistreatment questionnaire was constructed for the purpose of the study based on Aroas (2018) qualitative study conducted with 50 - 60-year-old women who suffered teacher mistreatment and were affected emotionally. The open-ended questions were transformed into 20 -items using a scale of 1 (never) to 5 (almost always). For example, two of the items were: "school was a traumatic experience for me", "Till this day I fear that people will view me in the same way teachers viewed me"; "My self-confidence could have been higher if not for the teachers I met during my studies". Alpha Cronbach reliability coefficient here was .91 .

Procedure

Students in a multidisciplinary program in a college in northern Israel received a link to the survey. Using a snowball approach, the students were asked to invite family members, friends, and acquaintances to participate in the study. Likewise, the link was distributed via WhatsApp groups and Facebook. The sample was limited to those at least 18 years old. Participants were informed that their responses would remain anonymous and that participation was voluntary. As such, the study was approved by the Ethical Review Board at the senior author's institute.

\subsection{Analysis Plan}

The data was analyzed using SPSS 25 . Descriptive statistics, including means standard deviations, and intercorrelations between variables were used to analyze the hypotheses. In addition, the Process procedure was used to test the mediation hypothesis (Preacher and Hayes, 2004).

\section{Results}

Based on an analysis of 377 student participants, Table 1 summarizes the means, standard deviations, intercorrelations among study variables in the analysis. All reported intercorrelations were in the expected directions and significant at $p$ $<.01$. In particular, the correlation between teachers' emotional mistreatment and long-term emotional impact was .41 (See Table 2).

Of the participants in the study, $31 \%(\mathrm{n}=118)$ reported experiencing at least one incident in which they had been psychologically mistreated by teacher in the school. The most reported types of psychological maltreatment involved being picked last by the teacher (69\%), teacher yelling at me (64.2\%), being ignored by a teacher (41.6\%) and a teacher would not help when asked for help (39\%). 
Table 1. Means, standard deviations, and intercorrelations for study variables $(\mathrm{N}=377)$.

\begin{tabular}{lccccc}
\hline & $M$ & $S S D$ & 1 & 2 & 3 \\
\hline Variable & & & & & \\
1. Mistreatment & 1.40 & 0.57 & .79 & $-.17^{* *}$ & $.41^{* *}$ \\
2. EI & 3.99 & 0.59 & & .88 & $-.25^{* *}$ \\
3. Long-term & 1.87 & 0.70 & & & .91 \\
\hline
\end{tabular}

${ }^{* *} p<.01$ Coefficient alpha in parenthesis.

Table 2. Frequency of types of psychological maltreatment reported by students.

\begin{tabular}{|c|c|c|c|c|}
\hline & $\begin{array}{l}\text { Happened } \\
1 \text { Time }\end{array}$ & $\begin{array}{l}\text { Happened } \\
2 \text { to } 3 \\
\text { Times }\end{array}$ & $\begin{array}{l}\text { Happened } \\
4 \text { or More } \\
\text { Times }\end{array}$ & $\begin{array}{l}\text { Total } \\
\text { Per Item }\end{array}$ \\
\hline $\begin{array}{l}\text { Psychological Mistreatment } \\
\text { Subscale Items }\end{array}$ & $\%$ & $\%$ & $\%$ & $\%$ \\
\hline 1. A teacher picked me last & 22 & 24.7 & 22.3 & 69 \\
\hline $\begin{array}{l}\text { 2. A teacher would not help me when I } \\
\text { asked for help }\end{array}$ & 19.1 & 12.5 & 7.4 & 39 \\
\hline $\begin{array}{l}\text { 3. A teacher did not allow me to be } \\
\text { part of special activities (art, gym, } \\
\text { recess, etc.) }\end{array}$ & 12.7 & 4.8 & 1.3 & 18.8 \\
\hline $\begin{array}{l}\text { 4. A teacher made me stay alone, away } \\
\text { from everyone else }\end{array}$ & 9 & 2.4 & 0.5 & 11.9 \\
\hline 5. A teacher ignored me & 23.3 & 14.3 & 4 & 41.6 \\
\hline 6. A teacher yelled at me & 31.3 & 23.1 & 9.8 & 64.2 \\
\hline $\begin{array}{l}\text { 7. A teacher called me mean names, } \\
\text { made fun of me, or teased me in a } \\
\text { hurtful way }\end{array}$ & 11.9 & 5.6 & 2.4 & 19.9 \\
\hline $\begin{array}{l}\text { 8. A teacher said mean things about } \\
\text { my family }\end{array}$ & 5.3 & 0.8 & 0.5 & 6.6 \\
\hline $\begin{array}{l}\text { 9. A teacher made fun of me because of } \\
\text { my race or the color of my skin }\end{array}$ & $\mathrm{f}_{3.4}$ & 1.3 & 0.3 & 5 \\
\hline
\end{tabular}

As far as the long-term emotional impact scale, the most reported long-term impact items (on a 1-5 scale) were feeling defensive (3.56), feeling a constant need to prove my worth (3.14) and it is important for me not to be perceived as lazy (3.06).

Using the Process procedure in SPSS (Preacher and Hayes, 2004) to examine the proposed model, findings showed that the two variables (mistreatment and EI) explained about $20 \%$ of the variance of the long-term emotional impact ( $p$ $<.001)$. A closer look at mediation effects showed that EI acted as a significant mediator in the model with an indirect effect of .03 (Confidence interval, Lower limit $=.01$ and Upper limit $=.07)$. The direct effect between mistreatment and long-term emotional impact remained significant, $.38(p<.01)$. Thus, EI serves as a partial mediator in the model. 


\section{Discussion}

The present study's focus was to examine the links between teacher mistreatment and its long-term emotional impact on students by suggesting EI as a mediator and partial explanation for this link. Data collected from 377 young adults showed that the percentage of students experiencing at least one incident of teacher mistreatment (31\%), and the most frequent types of abuse (being picked up, being yelled at, and not receiving help) were similar to findings in other studies (Hughes et al., 2001; Nearchou, 2018; Theoklitou et al., 2012; Twemlow and Fonagy, 2005).

In light of the first research hypothesis, teacher emotional mistreatment was positively correlated with long term emotional impact. This finding is consistent with the few available studies of long-term impact of teacher mistreatment (Brendgen et al., 2006; Brendgen et al., 2007), as well as with studies of longterm impacts as a result of family emotional mistreatment (O'Dougherty-Wright, 2014), peer to peer bullying (Cowie \& Mayers, 2017) and workplace mistreatment (Itzkovich, 2015). Yates (2007) proposed that emotional abuse can be conceptualized as a type of chronic relational adversity. Recurrent hostile, degrading, indifferent and unpredictable emotional interactions between a caregiver (such as a teacher) and a child can create stress that in turn evokes adaptational difficulties and has the potential for long term negative psychological items.

Secondly, the hypothesis that teacher emotional mistreatment will be negatively correlated with EI, was also confirmed. This finding adds to the small body of literature on the impact of abusive experiences on EI levels (Mattar, 2018; Pearson \& Porath, 2009; Thompson, 2010; Zhao et al., 2020) and extends it to teachers' mistreatment. Thompson (2010) explained that stress, including stress induced by abusive experiences, has an enormous impact on cognitive and emotional resources and reduces the ability to use EI. Indeed, Gibb et al. (2007) found that long-term emotional impact of mistreatment was fully mediated by increased negative automatic thoughts and decreased positive automatic thoughts, which can serve as a marker of reduced EI (Mayer \& Salovey, 1997). Other studies have reported findings consistent with the present results. More specifically, childhood maltreatment was found to affect people's ability of emotional regulation (Heleniak et al., 2016), reduce the ability to assess others' emotions, as well as one's own emotions, which in turn may have negative impact on general levels of EI (Mattar, 2018). Lea et al. (2019) further noted that EI is only adaptive in certain contexts and depends on the stressor type. It is therefore possible that given the significance of teacher-student relations, teacher mistreatment is a stressor which negatively effects the use of EI.

In line with the third study hypotheses, EI was negatively correlated with emotional long-term impacts of mistreatment and served as a mediator in the mistreatment-emotional long-term effect association. From a practical perspective, this implies meaning that If EI levels remains high, a person can use adaptive responses to reduce negative outcomes (Lea et al., 2019). However, if EI decreases 
following mistreatment, the long-term emotional effects are greater. When emotional abuse takes place, emotional resources such as ability to identify, use, understand and regulate emotions (Mayer \& Salovey, 1997), are reduced, leaving fewer resources for effectively coping with adverse experiences (Lea et al., 2019). Furthermore, childhood mistreatment may impair social cognition (Mattar, 2018), another EI component which is related to the ability to identify and understand the emotions of others (Goleman, 2006) and harm long-term relationships.

From another perspective, the reduction of EI may imply a decline in positive emotion frequency. Fewer positive emotions, in turn, weaken the victims' coping ability when facing adverse events and makes it more difficult to build up personal resources for confronting and dealing with future adversities and setbacks (Fredrickson \& Joiner, 2002). At the same time, lower levels of EI may make people produce more negative emotions in their lives, which will make them more likely to suffer from depression and anxiety later in life (Zhao et al., 2020).

Parents, as well as society at large, rely on teachers to provide children with cognitive, emotional, and behavioral development and allow them to flourish in a safe and supportive climate. While this is also the aim of most schools and teachers, unfortunately it is not the case when teacher mistreatment towards students takes place. Indeed, the school may be the first place that children experience emotional abuse (Nesbit \& Philpott, 2002). While studies show that teachers' emotional mistreatment towards students is a widespread problem with profound negative impact (Kizltepe et al., 2020), our paper is one of the first to study the topic rigorously. As such, determining the long-term impact, and, in particular, the effect on social-emotional skills, is quite essential as it helps explain various types of behavior in adults that may be prevented if the process leading to such negative outcomes was better understood.

\section{Limitations and Further Studies}

Several research limitations warrant mentioning. First, the cross-sectional nature of the study might have undermined definitive statements about causality. For example, our analysis implies that teacher mistreatment lowered students' EI levels. However, it may be that those with lower EI are more inclined to become a target of mistreatment or suffer long-term emotional impacts more than others. Secondly, the current study used single-source self-report measures for all constructs in the research model, which implies that common-method variance may be of concern. However, as mistreatment and reactions to it were the focus of the study, self-report does seem to be the appropriate measure. Indeed, future studies may take a longitudinal, rather than retrospective, perspective allowing for reactions of the individual over time and to different aspects of his/her life.

Lastly, the sample of Arabs women students was drawn from a relatively small area with a somewhat homogenous background. To determine whether are results generalize a replication study conducted with male students or national representative sample is therefore warranted. In view of the present findings, we 
hope future research will further elucidate on the role of EI in explaining how mistreatment leads to negative effects in the field of education similar to other fields.

\section{Conclusion}

In conclusion, teachers' mistreatment towards students, an often-overlooked angle of school experience, has been shown to have a severe emotional effect on children and young adults. Despite its limitations, the current study elaborates and expands on previous studies on child mistreatment by showing, for the first time, the role EI plays in mediating between teachers' mistreatment and its longterm emotional impacts. Often the effect is subliminal and as it has the potential to reduce EI, a set of essential skills which are related to children's success and future well-being (CASEL, 2018; OECD, 2018) may be lost.

\section{Recommendations}

We suggest that this added awareness should be incorporated into teachers' trainings to help raise awareness of the behaviors which may harm students and the potentially strong negative emotional impact of mistreatment. Additionally, in light of the association between high EI levels and teachers' ability to form positive relationships and supportive class climate to students, we suggest actively developing teachers' EI through trainings. Furthermore, alongside efforts to reduce mistreatment, incorporating Social Emotional Learning (SEL) initiatives (CASEL, 2018) for students can help develop resources that will protect them against the negative short and long-term emotional impacts of mistreatment.

\section{Conflicts of Interest}

The authors declare no conflicts of interest regarding the publication of this paper.

\section{References}

Aluede, O., Ojugo, A. I., \& Okoza, J. (2012). Emotional Abuse of Secondary School Students by Teachers in Edo State, Nigeria. Research in Education, 88, 29-39. https://doi.org/10.7227/RIE.88.1.3

Aroas, S. (2018). Teachers Psychological-Emotional Mistreatment of Students. In Y. Optalka (Ed.), Emotions in Teaching and School Management, a Collection of Articles (pp. 120-158). Tel Aviv-Yafo: Mofet Institute.

Balluerka, N., Gorostiaga, A., Alonso-Arbiol, I., \& Aritzeta, A. (2016). Peer Attachment and Class Emotional Intelligence as Predictors of Adolescents' Psychological Well-Being: A Multilevel Approach. Journal of Adolescence, 53, 1-9. https://doi.org/10.1016/j.adolescence.2016.08.009

Bar-On, R. (2006). The Emotional Quotient Inventory (EQ-i): Technical Manual. Multi-Health Systems.

Ba-Saddik, A. S. S., \& Hattab, A. S. (2012). Emotional Abuse towards Children by Schoolteachers in Aden Governorate, Yemen: A Cross-Sectional Study. BMC Public Health, 
12, 647. https://doi.org/10.1186/1471-2458-12-647

Beltrán-Catalán, M., Zych, I., Ortega-Ruiz, R., \& Llorent, V. J. (2018). Victimisation through Bullying and Cyberbullying: Emotional Intelligence, Severity of Victimisation and Technology Use in Different Types of Victims. Psicothema, 30, 183-188.

Benbenishty, R., Zeira, A., Astor, R. A., \& Khoury-Kassabri, M. (2002). Maltreatment of Primary School Students by Educational Staff in Israel. Child Abuse \& Neglect, 26, 12911309. https://doi.org/10.1016/S0145-2134(02)00416-7

Bibi, Z., \& Karim, J. (2013). Workplace Incivility and Counterproductive Work Behavior: Moderating Role of Emotional Intelligence. Pakistan Journal of Psychological Research, 28, 317-334.

Brackett, M. A., \& Katulak, N. A. (2006). Emotional Intelligence in the Classroom: SkillBased Training for Teachers and Students. In J. Ciarrochi, \& J. D. Mayer (Eds.), Applying Emotional Intelligence: A Practitioner's Guide (pp. 1-27). New York: Psychology Press.

Brackett, M. A., \& Salovey, P. (2006). Measuring Emotional Intelligence with the Mayer-Salovery-Caruso Emotional Intelligence Test (MSCEIT). Psicothema, 18, 34-41.

Brendgen, M., Wanner, B., \& Vitaro, F. (2006). Verbal Abuse by the Teacher and Child Adjustment from Kindergarten through Grade 6. Pediatrics, 117, 1585-1598. https://doi.org/10.1542/peds.2005-2050

Brendgen, M., Wanner, B., Vitaro, F., Bukowski, W. M., \& Tremblay, R. E. (2007). Verbal Abuse by the Teacher during Childhood and Academic, Behavioral, and Emotional Adjustment in Young Adulthood. Journal of Educational Psychology, 99, 26-38. https://doi.org/10.1037/0022-0663.99.1.26

Chen, J. K., \& Whi, H. S. (2011). Student Victimization by Teachers in Taiwan: Prevalence and Associations. Child Abuse \& Neglect, 35, 382-390. https://doi.org/10.1016/j.chiabu.2011.01.009

Collaborative for Academic, Social, and Emotional Learning (CASEL) (2018). What Is $S E L$ ? https://casel.org/sel-framework/

Cowie, H., \& Myers, C. A. (Eds.) (2017). School Bullying and Mental Health: Risks, Intervention and Prevention. London: Routledge. https://doi.org/10.4324/9781315537733

Dahal, N., Luitel, B. C., \& Pant, B. P. (2019). Teacher-Students Relationship and Its Potential Impact on Mathematics Learning. Mathematics Education Forum Chitwan, 4, 35-53. https://doi.org/10.3126/mefc.v4i4.26357

Dewaele, J. M., Gkonou, C., \& Mercer, S. (2018). Do ESL/EFL Teachers' Emotional Intelligence, Teaching Experience, Proficiency and Gender Affect Their Classroom Practice? In J. M. Agudo (Ed.), Emotions in Second Language Teaching (pp. 125-141). Cham: Springer. https://doi.org/10.1007/978-3-319-75438-3 8

Fernandez-Berrocal, P., \& Ruiz, D. (2008). Emotional Intelligence in Education. Electronic Journal of Research in Educational Psychology, 6, 421-436.

Fredrickson, B. L., \& Joiner, T. (2002). Positive Emotions Trigger Upward Spirals toward Emotional Well-Being. Psychological Science, 13, 172-175. https://doi.org/10.1111/1467-9280.00431

Gasser, L., Grütter, J., Buholzer, A., \& Wettstein, A. (2018). Emotionally Supportive Classroom Interactions and Students' Perceptions of Their Teachers as Caring and Just. Learning and Instruction, 54, 82-92. https://doi.org/10.1016/j.learninstruc.2017.08.003

Gehlbach, H., Brinkworth, M. E., \& Harris, A. D. (2012). Changes in Teacher-Student Relationships. British Journal of Educational Psychology, 82, 690-704.

https://doi.org/10.1111/j.2044-8279.2011.02058.x 
Geiger, B. (2017). Sixth Graders in Israel Recount Their Experience of Verbal Abuse by Teachers in the Classroom. Child Abuse \& Neglect, 63, 95-105. https://doi.org/10.1016/j.chiabu.2016.11.019

Gibb, B. E., Benas, J. S., Crossett, S. E., \& Uhrlass, D. J. (2007). Emotional Maltreatment and Verbal Victimization in Childhood: Relation to Adults' Depressive Cognitions and Symptoms. Journal of Emotional Abuse, 7, 59-73. https://doi.org/10.1300/J135v07n02 04

Goldman, J. D. G. (2010). The New Sexuality Education Curriculum for Queensland Primary Schools. Sex Education, 10, 47-66. https://doi.org/10.1080/14681810903491370

Goleman, D. (2006). Emotional Intelligence. New York: Bantam Books.

Hamre, B. K., \&. Pianta, R. (2001). Early Teacher-Child Relationships and the Trajectory of Children's School Outcomes through Eighth Grade. Child Development, 72, 625-638. https://doi.org/10.1111/1467-8624.00301

Haskett, R. (2003). Emotional Intelligence and Teaching Success in Higher Education. Doctoral Dissertation, Bloomington, IN: Indiana University.

Heleniak, C., Jenness, J. L., Vander Stoep, A., McCauley, E., \& McLaughlin, K. A. (2016). Childhood Maltreatment Exposure and Disruptions in Emotion Regulation: A Transdiagnostic Pathway to Adolescent Internalizing and Externalizing Psychopathology. Cognitive Therapy and Research, 40, 394-415. https://doi.org/10.1007/s10608-015-9735-z

Hicks, J., Jennings, L., Jennings, S., Berry, S., \& Green, D. A. (2018). Middle School Bullying: Student Reported Perceptions and Prevalence. Journal of Child and Adolescent Counseling, 4, 195-208. https://doi.org/10.1080/23727810.2017.1422645

Hogan, T., Ricci, C., \& Ryan, T. G. (2019). Respecting Students: Abusive Classroom Teacher Verbal Behaviour. Journal of Pedagogical Research, 3, 151-165. https://doi.org/10.33902/jpr.v3i3.139

Hughes, J. N., Cavell, T. A., \& Willson, V. (2001). Further Support for the Developmental Significance of the Quality of the Teacher-Student Relationship. Journal of School Psychology, 39, 289-301. https://doi.org/10.1016/S0022-4405(01)00074-7

Hyman, I. A., \& Snook, P. (2002). My Worst School Experience Scale (MWSE). Los Angeles: Western Psychological Services.

Hyman, I. A., \& Snook, P. A. (1999). Dangerous Schools. What We Can Do about the Physical and Emotional Abuse of Our Children. San Francisco, CA: Jossey-Bass Publishers.

Itzkovich, Y. (2015). Uneconomic Relationships: The Dark Side of Interpersonal Relationship in Organization. Tel Aviv: Resling.

Itzkovich, Y., \& Dolev, N. (2017). The Relationships between Emotional Intelligence and Perceptions of Faculty Incivility in Higher Education. Do Men and Women Differ? Current Psychology, 36, 905-918. https://doi.org/10.1007/s12144-016-9479-2

Itzkovich, Y., Alt, D., \& Dolev, N. (2020). The Challenges of Academic Incivility: Social-Emotional Competencies and Redesign of Learning Environments as Remedies. Cham: Springer Nature. https://doi.org/10.1007/978-3-030-46747-0

Kelchtermans, G. (2016). The Emotional Dimension in Teachers' Work Lives: A Narrative-Biographical Perspective. In M. Zembylas, \& P. Schutz (Eds.), Methodological Advances in Research on Emotion and Education (pp. 31-42). Cham: Springer. https://doi.org/10.1007/978-3-319-29049-2 3

Kiziltepe, R., Irmak, T. Y., Eslek, D., \& Hecker, T. (2020). Prevalence of Violence by Teachers and Its Association to Students' Emotional and Behavioural Problems and School Performance: Findings from Secondary School Students and Teachers in Tur- 
key. Child Abuse \& Neglect, 107, Article ID: 104559. https://doi.org/10.1016/j.chiabu.2020.104559

Kokkinos, C. M., \& Kipritsi, E. (2012). The Relationship between Bullying, Victimization, Trait Emotional Intelligence, Self-Efficacy and Empathy among Preadolescents. Social Psychology of Education, 15, 41-58. https://doi.org/10.1007/s11218-011-9168-9

Lea, R. G., Davis, S. K., Mahoney, B., \& Qualter, P. (2019). Does Emotional Intelligence Buffer the Effects of Acute Stress? A Systematic Review. Frontiers in Psychology, 10, 810. https://doi.org/10.3389/fpsyg.2019.00810

Leberecht, T. (2018, July 22). The New Emotions of the New Machine Age: Will AI and Robots Change How and What We Can Feel? Psychology Today.

https://www.psychologytoday.com/us/blog/the-romance-work/201807/the-new-emotio ns-the-new-machine-age

Longobardi, C., Settanni, M., Prino, L. E., \& Gastaldi, F. G. M. (2015). Emotionally Abusive Behavior in Italian Middle School Teachers as Identified by Students. Journal of Interpersonal Violence, 33, 1327-1347. https://doi.org/10.1177/0886260515615144

MacCann, C., Jiang, Y., Brown, L. E., Double, K. S., Bucich, M., \& Minbashian, A. (2020). Emotional Intelligence Predicts Academic Performance: A Meta-Analysis. Psychological Bulletin, 146, 150-186. https://doi.org/10.1037/bul0000219

MacFarlane, M. (2018). Need for and Interest in Social and Emotional Aspects of Learning. Planning Evidence-Based Professional Development. Doctoral Dissertation, Halifax: Mount Saint Vincent University.

http://140.230.24.101:8080/xmlui/bitstream/handle/10587/1921/MaggieMacFarlaneMA SPThesis2018.pdf? sequence $=1$ \&isAllowed $=\mathrm{y}$

Mattar, J. W. (2018). The Difference in Emotional Intelligence in Relation to Levels of Maltreatment of Jordanian Secondary School Students. International Journal of Adolescence and Youth, 23, 61-69. https://doi.org/10.1080/02673843.2017.1292926

Mayer, J. D., \& Salovey, P. (1997). What Is Emotional Intelligence? In P. Salovey, \& D. Sluyter (Eds.), Emotional Development and Emotional Intelligence: Educational Implication (pp. 3-31). New York: Basic Books.

McEachern, A. G., Aluede, O., \& Kenny, M. C. (2008). Emotional Abuse in the Classroom: Implications and Interventions for Counselors. Journal of Counseling \& Development, 86, 3-10. https://doi.org/10.1002/j.1556-6678.2008.tb00619.x

Miao, C., Humphrey, R. H., \& Qian, S. (2017). A Meta-Analysis of Emotional Intelligence and Work Attitudes. Journal of Occupational and Organizational Psychology, 90, 177202. https://doi.org/10.1111/joop.12167

Nathanson, L., Rivers, S. E., Flynn, L. M., \& Brackett, M. A. (2016). Creating Emotionally Intelligent Schools with Ruler. Emotion Review, 8, 305-310. https://doi.org/10.1177/1754073916650495

Nearchou, N. (2018) Resilience Following Emotional Abuse by Teachers: Insights from a Cross-Sectional Study with Greek Students. Child Abuse \& Neglect, 78, 96-106. https://doi.org/10.1016/j.chiabu.2017.10.012

Nesbit, W. C., \& Philpot, D. F. (2002), Confronting Subtle Emotional Abuse in Classrooms. Guidance and Counselling, 17, 32-38.

Nias, J. (1996). Thinking about Feeling: The Emotion in Teaching. Cambridge Journal of Education, 26, 293-306. https://doi.org/10.1080/0305764960260301

O’Dougherty-Wright, M. (Ed.) (2014). Childhood Emotional Abuse: Mediating and Moderating Processes Affecting Long-Term Impact. New York: Routledge.

https://doi.org/10.4324/9781315877471 
Organization for Economic Co-operation and Development (OECD) (2018). The Future of Education and Skills: Education 2030. OECD.

Palomera, R., Fernandez-Berrocal, P., \& Brackett, M. A. (2008). Emotional Intelligence as a Basic Competency in Pre-Service Teacher Training: Some Evidence. Electronic Journal of Research in Educational Psychology, 6, 437-454.

Paul, J. L., \& Smith, T. J. (Eds.) (2000). Stories Out of School: Memories and Reflections on Care and Cruelty in the Classroom. New York: Ablex Publishing Corporation.

Pearson, C. M., \& Porath, C. L. (2009). The Cost of Bad Behavior: How Incivility Is Damaging Your Business and What to Do about It. Human Resource Management International Digest, 18. https://doi.org/10.1108/hrmid.2010.04418fae.002

Perry, C., \& Ball, I. (2007). Dealing Constructively with Negatively Evaluated Emotional Situations: The Key to Understanding the Different Reactions of Teachers with High and Low Levels of Emotional Intelligence. Social Psychology of Education, 10, 443-454. https://doi.org/10.1007/s11218-007-9025-Z

Preacher, K. J., \& Hayes, A. F. (2004). SPSS and SAS Procedures for Estimating Indirect Effects in Simple Mediation Models. Behavior Research Methods, Instruments, \& Computers, 36, 717-731. https://doi.org/10.3758/BF03206553

Reza, H., Bromfield, N. F., Sultana, S., \& Kahn, M. R. (2020). Child Maltreatment in Bangladesh: Poverty, Social Class, and the Emotional Abuse of Elementary School Children by Teachers. Children and Youth Services Review, 116, Article ID: 105195. https://doi.org/10.1016/j.childyouth.2020.105195

Rodrigo-Ruiz, D. (2016). Effect of Teachers' Emotions on Their Students: Some Evidence. Journal of Education \& Social Policy, 3, 73-79.

Roorda, D. L., Koomen, H. M., Spilt, J. L., \& Oort, F. J. (2011). The Influence of Affective Teacher-Student Relationships on Students' School Engagement and Achievement: A Meta-Analytic Approach. Review of Educational Research, 81, 493-529.

https://doi.org/10.3102/0034654311421793

Rutledge, S. A., Cohen-Vogel, L., Osborne-Lampkin, L. T., \& Roberts, R. L. (2015). Understanding Effective High Schools: Evidence for Personalization for Academic and Social Emotional Learning. American Educational Research Journal, 52, 1060-1092. https://doi.org/10.3102/0002831215602328

Schwartz, F. (2016). Prediction of Emotional Intelligence and Theory of Mind in Adults Who Have Experienced Childhood Maltreatment. Unpublished Master's Thesis, Winnipeg: University of Manitoba.

Skalická, V., Stenseng, F., \& Wichstrøm, L. (2015). Reciprocal Relations between Student-Teacher Conflict, Children's Social Skills and Externalizing Behavior: A Three-Wave Longitudinal Study from Preschool to Third Grade. International Journal of Behavioral Development, 39, 413-425. https://doi.org/10.1177/0165025415584187

Smith, P. K., \& Brain, P. (2000). Bullying in Schools: Lessons from Two Decades of Research. Aggressive Behavior, 26, 1-9. https://doi.org/10.1002/(SICI)1098-2337(2000)26:1<1::AID-AB1>3.0.CO;2-7

Stronge, J. H. (2007). Qualities of Effective Teachers (2nd ed.). Alexandria: ASCD.

Theoklitou, D., Kabitsis, N., \& Kabitsi, A. (2012). Physical and Emotional Abuse of Primary School Children by Teachers. Child Abuse and Neglect, 36, 64-70. https://doi.org/10.1016/j.chiabu.2011.05.007

Thompson, H. L. (2010). The Stress Effect: Why Smart Leaders Make Dumb DecisionsAnd What to Do about It. Hoboken, NJ: John Wiley \& Sons. https://doi.org/10.1037/e581112010-001

Timostsuk, I., \& Usaste, A. (2012). The Role of Emotions in Student Teachers' Profes- 
sional Identity. European Journal of Teacher Education, 35, 421-433. https://doi.org/10.1080/02619768.2012.662637

Twemlow, S. W., \& Fonagy, P. (2005). The Prevalence of Teachers Who Bully Students in Schools with Differing Levels of Behavioural Problems. American Journal of Psychiatry, 162, 2387-2389. https://doi.org/10.1176/appi.ajp.162.12.2387

Twemlow, S. W., Fonagy, P., Campbell, C., \& Sacco, F. C. (2017). Creating a Peaceful School Learning Environment. In H. Steele, \& M. Steele (Eds.), Handbook of Attachment-Based Interventions (pp. 360-374). New York: Guilford Press.

Wang, H., Hall, N. C., Goetz, T., \& Frenzel, A. C. (2017). Teachers' Goal Orientations: Effects on Classroom Goal Structures and Emotions. British Journal of Educational Psychology, 87, 90-107. https://doi.org/10.1111/bjep.12137

Whitted, K. S. (2005). Student Reports of Physical and Psychological Maltreatment in Schools: An Under Explored Aspect of Student Victimization in Schools. Doctoral Dissertation, Knoxville, TN: Tennessee Research and Creative Exchange, University of Tennessee. https://trace.tennessee.edu/utk graddiss/2317

Whitted, K. S., \& Dupper, D. R. (2008). Do Teachers Bully Students? Findings from a Survey of Students in an Alternative Education Setting. Education and Urban Society, 40, 329-341. https://doi.org/10.1177/0013124507304487

Wong, C. S., \& Law, K. S. (2002). The Effects of Leader and Follower Emotional Intelligence on Performance and Attitude: An Exploratory Study. The Leadership Quarterly, 13, 243-274. https://doi.org/10.1016/S1048-9843(02)00099-1

Yates, T. M. (2007). The Developmental Consequences of Child Emotional Abuse: A Neurodevelopmental Perspective. Journal of Emotional Abuse, 7, 9-34. https://doi.org/10.1300/J135v07n02 02

Zeidner, M., Matthews, G., \& Roberts, R. D. (2012). What We Know about Emotional Intelligence: How It Affects Learning, Work, Relationships, and Our Mental Health. Cambridge, MA: MIT Press.

Zhao, J., Xiang, Y., Zhang, W., Dong, X., Zhao, J., \& Li, Q. (2020). Childhood Maltreatment Affects Depression and Anxiety: The Mediating Role of Emotional Intelligence. International Journal of Mental Health and Addiction, 1-10. https://doi.org/10.1007/s11469-020-00297-x

Zysberg, L., Orenshtein, C., Gimmon, E., \& Robinson, R. (2017). Emotional Intelligence, Personality, Stress, and Burnout among Educators. International Journal of Stress Management, 24, 122-136. https://doi.org/10.1037/str0000028 